ORIGINAL ARTICLE

DOI $10.21608 /$ zumj.2019.13975.1275

\title{
Frequency of Cervical Intra-epithelial Neoplasia in Oral Contraceptive Pills Users in Zagazig University Hospitals
}

\author{
Attya M. Attya ${ }^{1^{*}}$, Ali E. Ali ${ }^{1}$, Hoda S. Abdel-Salam ${ }^{1}$, Mai M. Abdel-Wahab ${ }^{2}$ \\ 1: Department of Obstetrics and Gynecology, Faculty of Medicine, Zagazig University \\ 2: Department of Pathology, Faculty of Medicine, Zagazig University
}

Corresponding Author: Name

Attya Mohamed Attya Abdel-

Fattah.

E-mail:

attyamohamedattya@yahoo.com

$\begin{array}{ll}\text { Submit Date } & 2019-06-25 \\ \text { Revise Date } & 2019-07-19 \\ \text { Accept Date } & 2019-07-26\end{array}$

Background: Combined oral contraceptive pills (COCs) are widely used as contraceptive method. Some authors linked prolonged use of COCs to the development of cervical intra-epithelial neoplasia (CIN). However, this link need more investigations to be proven.

The aim of the study: was to assess the association between the long term use of combined oral contraceptive pills and the development of cervical intra-epithelial neoplasia.

Patients \& methods: This cross-sectional observational study was carried out in the outpatient clinic of the Obstetrics \& Gynecology Department at Zagazig University Hospitals and the Department of Pathology at the Faculty of Medicine, Zagazig University, Zagazig, Sharkia, Egypt, from December 2017 till January 2019. One hundred and thirty six women were included; All of them were currently using COCs or previously used it. Full history was taken from all the women, PAP smear was taken, fixed on glass slide by alcohol 95\%, then staining with Papanicolaou stain and finally interpretation of the results using Bethesda system 2014 was done.

Results: Abnormal PAP smear was correlated with the duration of COCs use, the longer the duration of COCs use, the higher the grade of abnormal PAP smear. Other factors that correlate positively with abnormal PAP smear in COCs users were older age, longer marital life and higher parity (>3). On the contrary, mode of delivery, history of cervical cauterization or complaint of vaginal discharge had no impact.

Conclusion: Positive association was noticed between the duration of COCs use and abnormal PAP smear and between its long term use and the higher grade of the abnormal PAP smear.

Keywords: Cervical intra-epithelial neoplasia, PAP smear, Combined oral contraceptive pills.

\section{INTRODUCTION}

Orane ancer cervix is an important global health issue. The World Health Organization and International agency on Cancer Research have estimated that 530,000 patientswere diagnosed with cancer cervix in 2012 worldwide, and there were approximately 275,000 deaths in $2012^{(1)}$. Cancer cervix is the fourth leading cancer in patientsglobally after breast, lung and colorectal cancers ${ }^{(2)}$ and the second most common cause of cancer mortality for patientsworldwide, with an estimated $88 \%$ of mortality occurring in developing countries (3). In general, higher incidences are found in developing countries, and these countries contribute $85 \%$ of reported cases annually (up to 450,000 new cases of invasive cancer of the cervix occur per year in these countries, leading to 275,000 deaths) ${ }^{(1)}$.

In Egypt, current estimates indicate that every year 866 patientsare diagnosed with cervical cancer and 373 die from the disease. Cervical cancer ranks as the $13^{\text {th }}$ most frequent cancer among patientsin Egypt and the $10^{\text {th }}$ most frequent cancer among patientsbetween 15 and 44 years of age ${ }^{(4)}$.

After the use of Papanicolaou smear in the 1940s and because of its long pre-invasive stage and effectiveness of its treatment, invasive cancer cervix has been considered as a preventable disease and its incidence and mortality rates have been declined. So, cytological screening of cervical smears is the 
most valuable screening program for cancer cervix has ever developed ${ }^{(5)}$.

Determination of risk factors of cervical intra-epithelial neoplasia (CIN) is a need, as their recognition will provide a good opportunity to create and implement multiple interventions suitable to detect both occurrence and progression of CIN (6). Combined oral contraceptive pill is the most common method used for contraception in the world ${ }^{[7]}$ and many epidemiological studies suggests that its use for a long time might increase the incidence of cancer cervix ${ }^{[8]}$. However, the World Health Organization did not recommend stopping the oral contraceptives use because it outweigh its risk [9]. Indeed, there is lack in evidence on the relationship between the use of oral contraceptive pills and the risk of cervical intra-epithelial neoplasia ${ }^{[10]}$ and therefore, the present study aims to investigate whether the use of combined oral contraceptive pills is associated with any risk or not.

\section{PATIENTS AND METHODS}

This cross-sectional observational study was carried out in the outpatient clinic of the Obstetrics \& Gynecology Department, Zagazig University Hospitals and the Department of Pathology, the Faculty of Medicine, Zagazig University, Zagazig, Sharkia, Egypt, from December 2017 till January 2019. One hundred and thirty six women were included. . All participants were aged 27 to 65 years and currently using combined oral contraceptive pills or previously used it for more than 5 years duration. Our exclusion criteria were pregnant women, cases of cervicitis, cases with history of previous or current malignant or premalignant lesions of the genital tract and cases with past history of subtotal hysterectomy or cervical conization.

After including participants that met the eligibility criteria and obtaining written informed consent, we took full history including personal, present, past, family, obstetric, contraceptive and menstrual history. The participants were advised to avoid having intercourse, using a tampon, douching or applying vaginal creams or lotions in the $24-48$ hours that preceeded cervical smear.
A speculum was then inserted into vagina. Cervical smear was collected using Ayre's spatula in the outpatient clinic. The spatula was inserted into the opening of the cervix and twirled around to collect a sample of cells from endocervix. A second sample was also collected from the surface of the cervix "the ectocervix" as part of the PAP smear. Fixation of the smear on a glass slide using Alcohol 95\% for 15 minutes. Staining of the slide with Papanicolaou stain at the Department of Pathology, the Faculty of Medicine, Zagazig university. Finally, the interpretation of the results using Bethesda system 2014 which is a system for reporting Pap smear results and cervical or vaginal cytologic changes ${ }^{[11]}$.

Written informed consent was obtained from all participants and the study was approved by the research ethical committee of Faculty of Medicine, Zagazig University. The work has been carried out in accordance with The Code of Ethics of the World Medical Association (Declaration of Helsinki) for studies involving humans.

Statistical analysis was performed using Statistical Program for Social Science (SPSS) version 25.0 for windows (SPSS Inc., Chicago, IL, USA), NCSS 12 for windows (NCSS LCC., Kaysville, UT, USA). Quantitative data of normal distribution were expressed as mean \pm standard deviation (Goldstein and Lumsden), whereas median and range (minimum - maximum) were calculated for not normally distributed quantitative data. Qualitative data were expressed as frequency and percentage. The following tests were done; Mann Whitney U test was used to compare differences between two independent groups when the dependent variable is continuous, but not normally distributed, Chi-square (X2) test also called Pearson's chi-square test or the chi-square test of association, was used to discover if there is a relationship between two categorical variables, Fisher Exact test is a test of significance that was used in the place of chi square test in 2 by 2 tables, especially in cases of small samples and A one-way analysis of variance (ANOVA) was used when comparing among more than two means if data is normally distributed. 


\section{RESULTS}

Abnormal Pap smear were found in 19 cases out of 136 COCs (14\%). 10 out of detected 19 cases showed ASCUS (7.4\%), LSIL was reported in 5 cases $(3.7 \%)$, HSIL was reported in 3 cases $(2.2 \%)$ and only 1 case of SCC (0.7\%) (Table 1). Abnormal PAP smear was correlated with the duration of COCs use, the longer the duration of COCs use, the higher the grade of abnormal PAP smear. Other factors that correlate positively with abnormal PAP smear in COC users were older age, longer marital life and higher parity (> 3). On the contrary, mode of delivery, history of cervical cauterization or complaint of vaginal discharge had no impact on frequency of CIN development. (Table 1)

This table shows that the age of patientsand duration of marriage are higher for those who had positive PAP smear results with $\mathrm{P}$ value for both $<0.001$ which is highly significant. Also it shows that mostly the patients with positive PAP smear results $(84.2 \%)$ had parity $>3$, with statistically significant difference between both groups regarding parity ( $\mathrm{P}$ value $<0.001$ ), while there is no statistical significance regarding the mode of previous deliveries. (Table 2)

This table shows that there was statistically significant association between the duration of COCs use and positive PAP smear results ( $\mathrm{P}$ value $<0.001)$. While there is no statistically significant association between positive PAP smear results and history of cervical cauterization and complaint of vaginal discharge. Also it shows that there was statistically significant association between the duration of COCs use and the higher grades of cervical cytology in PAP smear $(\mathrm{P}$ value $=0.046)$. While there is no statistically significant association between different grades of PAP smear results and history of cervical cauterization or complaint of vaginal discharge. (Table 3)

Table (1): Frequency of abnormal PAP smear results of the whole study population.

\begin{tabular}{|l|l|}
\hline PAP smear result & All patients \\
\hline Count (\%) & $136(100 \%)$ \\
\hline Negative for intra epithelial lesion & $\mathbf{1 1 7}(\mathbf{8 6 \% )}$ \\
\hline Positive for intra epithelial lesion & $\mathbf{1 9}(\mathbf{1 4 \% )}$ \\
\hline ASCUS & $10(7.4 \%)$ \\
\hline LSIL & $5(3.7 \%)$ \\
\hline HSIL & $3(2.2 \%)$ \\
\hline SCC & $1(0.7 \%)$ \\
\hline
\end{tabular}

ASCUS: Atypical Squamous Cell of Undetermined- significance

LSIL: Low grade Squamous Intraepithelial Lesion

HSIL: High grade Squamous Intraepithelial Lesion

SCC: Squamous cell carcinoma 
Table (2): Comparison between patients with positive and negative PAP smear results regarding the demographic and obstetric data.

\begin{tabular}{|c|c|c|c|c|}
\hline $\begin{array}{l}\text { Demographic } \\
\text { obstetric data }\end{array}$ & $\begin{array}{l}\text { Positive PAP } \\
\text { smear }\end{array}$ & $\begin{array}{l}\text { Negative } \quad \text { PAP } \\
\text { smear }\end{array}$ & \multirow[t]{2}{*}{ Test } & \multirow[t]{2}{*}{$\begin{array}{l}\text { P-value } \\
\text { (Sig.) }\end{array}$} \\
\hline Count & 19 & 117 & & \\
\hline \multicolumn{5}{|l|}{ Demographic data } \\
\hline \multicolumn{5}{|l|}{ Age (years) } \\
\hline Median (Range) & $47(35-65)$ & $37(27-41)$ & $6.185^{\bullet}$ & $<0.001(\mathrm{HS})$ \\
\hline \multicolumn{5}{|c|}{ Duration of marriage (years) } \\
\hline Median (Range) & $29(18-48)$ & $16(8-22)$ & $6.669 \bullet$ & $<0.001$ (HS) \\
\hline \multicolumn{5}{|l|}{ Obstetric data } \\
\hline \multicolumn{5}{|l|}{ Parity } \\
\hline$\leq \mathbf{3}$ & $3(15.8 \%)$ & $79(67.5 \%)$ & \multirow[t]{2}{*}{$18.272 \div$} & \multirow[t]{2}{*}{$<0.001(\mathrm{HS})$} \\
\hline$>\mathbf{3}$ & $16(84.2 \%)$ & $38(32.5 \%)$ & & \\
\hline \multicolumn{5}{|l|}{ Mode of previous deliveries } \\
\hline CS & $6(31.6 \%)$ & $52(44.4 \%)$ & \multirow[t]{2}{*}{$1.106+$} & \multirow[t]{2}{*}{$0.293(\mathrm{NS})$} \\
\hline VD & $13(68.4 \%)$ & $65(55.6 \%)$ & & \\
\hline
\end{tabular}

- Mann Whitney U test.

+ Chi-square test.

$\mathrm{p}<0.05$ is significant.

Sig.: significance.

Table (3): Comparison between patients with positive and negative PAP smear results and different grades of PAP smear results regarding the gynecological data.

\begin{tabular}{|c|c|c|c|c|c|c|c|c|}
\hline \multicolumn{2}{|c|}{ Gynecological data } & $\begin{array}{l}\text { Positive } \\
\text { PAP smear }\end{array}$ & \multicolumn{2}{|c|}{$\begin{array}{l}\text { Negative } \\
\text { PAP smear }\end{array}$} & \multirow{2}{*}{\multicolumn{2}{|c|}{ Test }} & \multirow{2}{*}{\multicolumn{2}{|c|}{$\begin{array}{l}\text { P-value } \\
\text { (Sig.) }\end{array}$}} \\
\hline Count & \multicolumn{2}{|l|}{19} & \multicolumn{2}{|l|}{117} & & & & \\
\hline \multicolumn{9}{|l|}{ COCs use duration (years) } \\
\hline Median (Range) & \multicolumn{2}{|c|}{$8(5-12)$} & \multicolumn{2}{|l|}{$6(5-7)$} & \multicolumn{2}{|c|}{$4.136^{\bullet}$} & \multicolumn{2}{|c|}{$<0.001(\mathrm{HS})$} \\
\hline \multicolumn{9}{|l|}{ History and symptoms } \\
\hline History of cervical cauterization & \multicolumn{2}{|c|}{$3(15.8 \%)$} & \multicolumn{2}{|c|}{$15(12.8 \%)$} & \multicolumn{2}{|l|}{$t^{\mathbf{F}}$} & \multicolumn{2}{|c|}{$0.718(\mathrm{NS})$} \\
\hline Symptoms (vaginal discharge) & \multicolumn{2}{|c|}{$12(63.2 \%)$} & \multicolumn{2}{|c|}{$75(64.1 \%)$} & \multicolumn{2}{|c|}{$0.006 \div$} & \multicolumn{2}{|c|}{$0.973(\mathrm{NS})$} \\
\hline Gynecological data & ASCUS & LSIL & HSIL & \multicolumn{2}{|c|}{$\mathrm{SCC}$} & \multirow{2}{*}{\multicolumn{2}{|c|}{ Test }} & \multirow{2}{*}{$\begin{array}{l}\text { P-value } \\
\text { (Sig.) }\end{array}$} \\
\hline Count & 10 & 5 & 3 & 1 & & & & \\
\hline \multicolumn{9}{|l|}{ COCs use duration (years) } \\
\hline Mean \pm SD & $6.6 \pm 1.6$ & $\begin{array}{l}7.8 \pm \\
0.8\end{array}$ & $\begin{array}{ll}9.7 & \pm \\
2.1 & \end{array}$ & \multicolumn{2}{|c|}{$8.0 \pm 0$} & \multicolumn{2}{|c|}{$3.377^{\mathrm{A}}$} & $\begin{array}{l}0.046 \\
(\mathrm{~S})\end{array}$ \\
\hline \multicolumn{9}{|l|}{ History and symptoms } \\
\hline Hx of cervical cauterization & $2(20 \%)$ & $\begin{array}{l}1 \\
(20 \%)\end{array}$ & $0(0 \%)$ & \multicolumn{2}{|c|}{$0(0 \%)$} & \multicolumn{2}{|c|}{$0.950 \ddagger$} & $0.813(\mathrm{NS})$ \\
\hline Symptoms (vaginal discharge) & $6(60 \%)$ & $\begin{array}{l}3 \\
(60 \%)\end{array}$ & $\begin{array}{l}2 \\
(66.7 \%)\end{array}$ & \multicolumn{2}{|c|}{$\begin{array}{l}1 \\
(100 \%)\end{array}$} & \multicolumn{2}{|c|}{$0.663 \hbar$} & $0.882(\mathrm{NS})$ \\
\hline
\end{tabular}

- Mann Whitney U test.

+ Chi-square test.

F Fisher's Exact test.

Ane-way Anova test.

$p<0.05$ is significant.

Sig.: significance. 


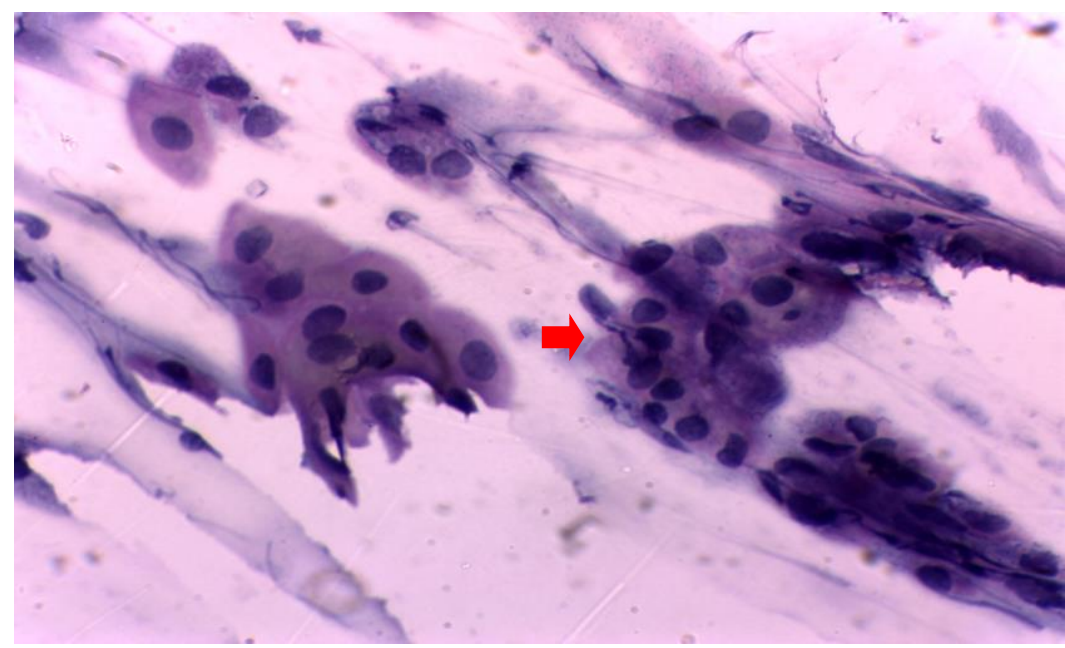

Figure (1): ASC-US. Cells with enlarged nuclei (2.5-3 times than intermediate cells), hyperchromatic chromatin (PAP x400).

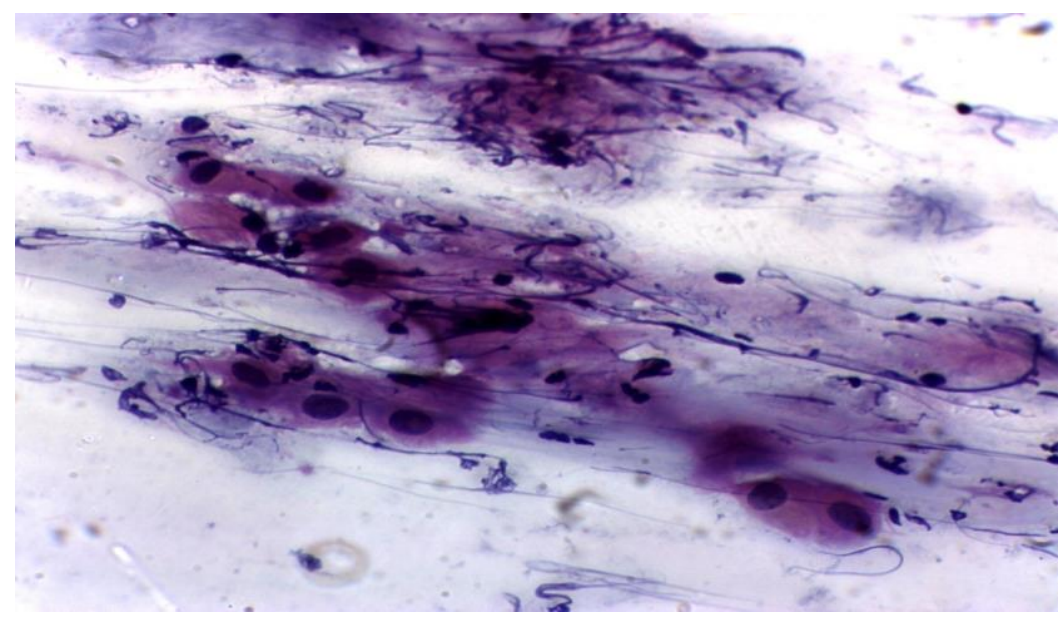

Figure (2): ASC-H. Clusters of squamous cells with high N/C ratio and nuclear irregularity (PAP X400).

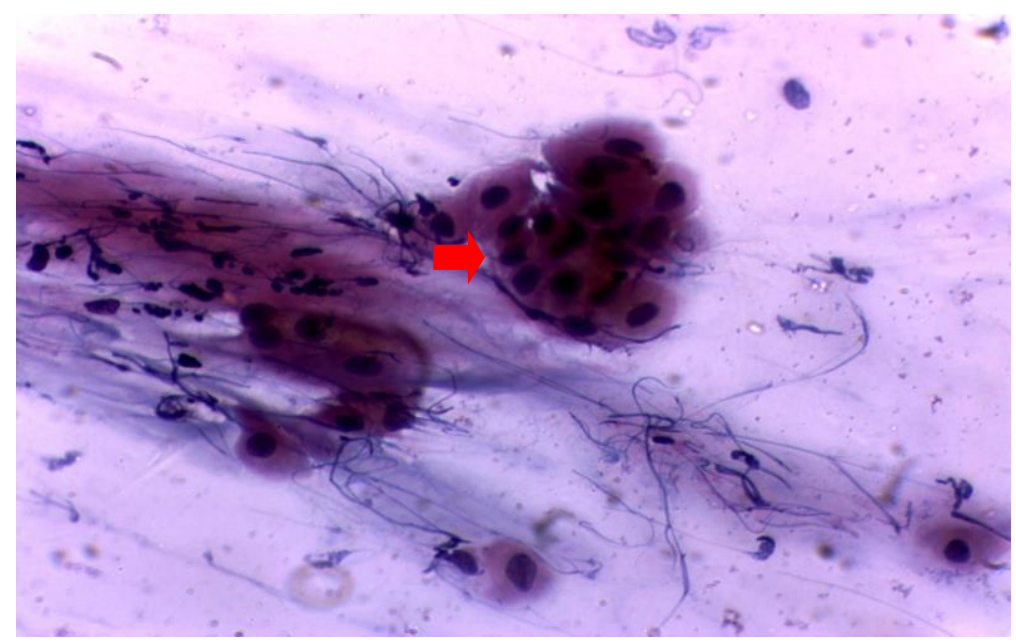

Figure (3): LSIL. Groups of squamous cells with enlarged hyperchromatic nuclei (PAPx400). 


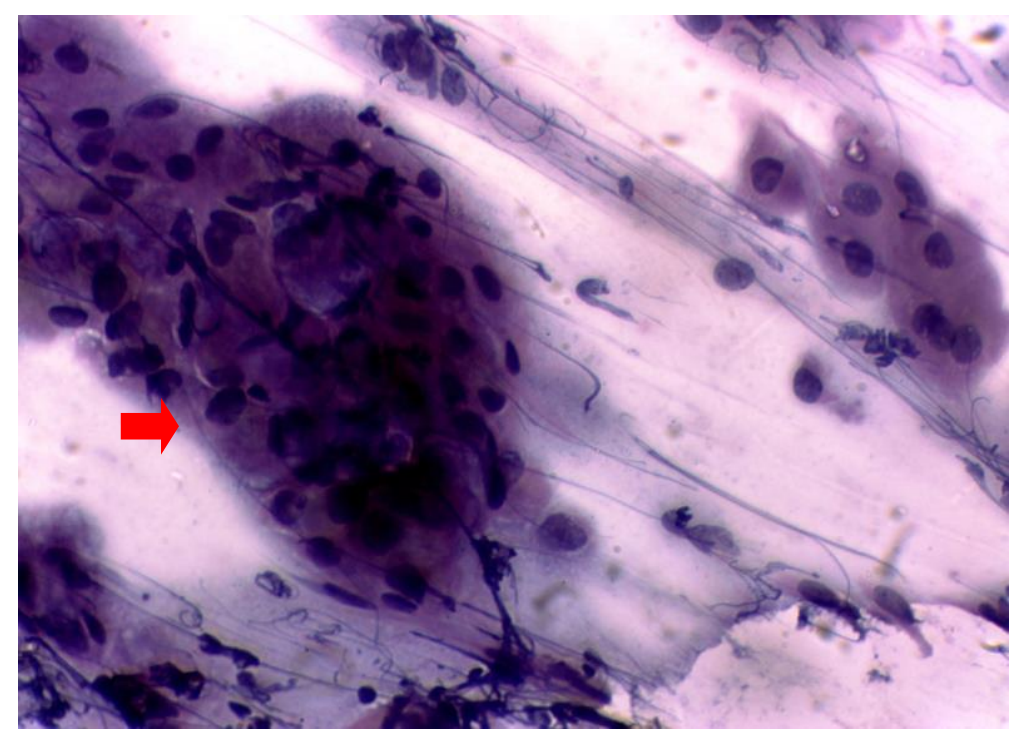

Figure (4): HSIL. Single and sheets of immature cells with high nuclear to cytoplasm ratio, hyperchromatic nuclei and scanty cytoplasm (PAP x400).

\section{DISCUSSION}

The present study was designed as a cross sectional study on 136 patientswho had used combined oral contraceptive pills attending at Zagazig university hospital outpatient clinics. In present study, the median age of patientswith positive PAP smear results was 47 years which is older than that of patientswith negative PAP smear results (37 years). Also, the frequency of positive PAP smear results increased with increasing the duration of marriage with statistically significant difference $(p<0.001$.$) In$ agreement with the present study, Wang et al. (6) found that the incidence of cervical epithelial changes was higher in patientsaged 56 - 65 years than those aged $36-45$ years.

In the present study, the frequency of positive PAP smear results increased with increasing parity $(84.2 \%$ for parity $>3$ versus $15.8 \%$ for parity $\leq 3$ ), and the result was statistically significant $(\mathrm{p}<0.001)$. In agreement with our results, El-Moselhy et al. ${ }^{[4]}$ observed that multiparity $>5$ is a significant risk factor for cervical epithelial changes (31.4\% in CIN group and $14 \%$ in non-CIN group) . On the contrary, Chih et al. ${ }^{[10]}$ found the mean for CIN group 1.9 while 2.1 for nonCIN group with no significant association between parity and these changes $(\mathrm{P}$ value $=$ 0.361).

In the present study, 117 patients( $86 \%)$ had negative results for intra-epithelial lesion, while 19 patients(14\%) had positive results for intra-epithelial lesions. 10 of them $(7.4 \%)$ were ASCUS, 5 (3.7\%) were LSIL, 3 (2.2\%) were HSIL and only $1(0.7 \%)$ case had SCC. Similar results were reported by Jasem et al. [12], who found that $(26.5 \%)$ of patientswho used COCs had positive PAP smear results versus $(8.3 \%)$ of patientswho had not used COCs. Also Roura et al. ${ }^{[13]}$ found that there is an increased risk of cervical changes in users of COCs. 169 cases with positive PAP smear results out of 121,117 cases who did not use COCs before (HR=1, 95\% CI: 0.71.3) versus 127 cases out of 17,384 cases who used COCs before (HR=1.8, 95\% CI: 1.42.4).

On the contrary, Binesh et al. ${ }^{[14]}$ found Abnormal PAP smear in $0.4 \%$ of COCs users versus $0.2 \%$ of non-users indicating no association between COCs consumption and positive PAP smear results $(\mathrm{P}$ value $=0.727$ ) The same conclusion was reached by ElMoselhy et al. ${ }^{[4]}$ who found no significant difference in the prevalence of COCs consumption among patients with positive PAP smear results $(96.1 \%)$ and patientswith 
negative PAP smear results (92\%). Both studies suggested that the HPV is the risk factor to cervical dysplasia with no direct effect to the consumption of COCs.

Other findings observed by $\mathbf{O h}$ et al. ${ }^{[15]}$ that COCs use had no effect on the risk of CIN I, but was associated with an increased risk of CIN II \& III. However, Sayed et al. ${ }^{[16]}$ even found a protective effect of COCs use on CIN. Another observation by Adhikari et al. [17] who found that the use of oral contraceptives does not increase the risk of CIN, but when CIN is established, COCs might instead be protective.

In this study, among patientswho had positive PAP smear, 6 patientshad previous CS and 13 patientshad only vaginal deliveries, while among patientswho had negative PAP smear, 52 patientshad previous $\mathrm{CS}$ and 65 patientshad only vaginal deliveries, with $\mathrm{P}$ value 0.293 which is non-significant.

In agreement with present study, Wang et al. ${ }^{[6]}$ concluded that parity did not differ significantly between patientswith CIN and healthy women.

On the contrary, El-Moselhy et al. (4) declared that vaginal delivery is a significant risk factor for cervical neoplasia. In CIN group $(n=49)$, normal vaginal delivery was in 47 cases. In normal group $(n=92)$, normal vaginal delivery was in 67 cases $(\mathrm{OR}=8.77$, 95\% ECL: 2.0-79.08).

In present study, the frequency of positive PAP smear results is correlated with the duration of COCs use with median duration of COCs consumption among patientswith positive PAP smear results is 8 years versus 6 years in patientswith negative PAP smear results. There is a positive relationship between the duration of COCs use and the grade of cervical lesion. The mean duration of COCs use among patientswho had positive PAP smear results was 6.6 years for ASCUS, 7.8 years for LSIL, 9.7 years for HSIL and 8 years for SCC.

In agreement with our study, El-Moselhy et al. ${ }^{[4]}$ stated that COCs consumption for more than 5 years is a significant risk factor for positive PAP smear results. In CIN group $(n=49), 26$ cases used COCs $>5$ years. In normal group ( $\mathrm{n}=92), 23$ cases used COCs $>5$ years $(\mathrm{OR}=3.39,95 \% \mathrm{CI}$ : $1.53-7.56)$. 
3. Parkhurst JO, Vulimiri M. Cervical cancer and the global health agenda: insights from multiple policy-analysis frameworks. Global public health. 2013 Dec 1;8(10):1093-108.

4. El-Moselhy EA, Salim SA, Hagrass SA. Prevalence and Risk Factors of Cervical Intraepithelial Neoplasia and Cervical Cancer among Ever Married Adult Females in Egypt: A Survey Study. J Compr Cancer Res. 2017;1(1):15.

5. Jafari Shobeiri M., Halimi M. , Dastranj A., Shahamphar J. Screening for cervical cancer and precancerous lesions in Tabriz. Medical Journal of The Islamic Republic of Iran (MJIRI). 2007 May 15;21(1):1-0.

6. Wang Z, Wang J, Fan J, Zhao W, Yang X, Wu L, Li D. Risk factors for cervical intraepithelial neoplasia and cervical cancer in Chinese women: large study in Jiexiu, Shanxi Province, China. Journal of Cancer. 2017;8(6):924.

7. Edlow AG, Bartz D. Hormonal contraceptive options for women with headache: a review of the evidence. Reviews In Obstetrics And Gynecology. 2010;3(2):55

8. Binesh F, Akhavan A, Pirdehghan A, Davoodi M. Does oral contraceptive pill increase the risk of abnormal Pap smear?. Iranian journal of reproductive medicine. 2013 Sep;11(9):761.

9. Gadducci A, Barsotti C, Cosio S, Domenici L, Riccardo Genazzani A. Smoking habit, immune suppression, oral contraceptive use, and hormone replacement therapy use and cervical carcinogenesis: a review of the literature. Gynecological Endocrinology. 2011 Aug 1;27(8):597-604.

10. Chih HJ, Lee AH, Colville L, Xu D, Binns CW. Condom and oral contraceptive use and risk of cervical intraepithelial neoplasia in Australian women. Journal of gynecologic oncology. 2014 Jul 1;25(3):183-7.

11. Nayar R, Wilbur DC. The pap test and Bethesda 2014. Acta cytologica. 2015;59(2):121-32.
12. Jasem AY, Mohsen S. The effect of chronic use of combined Oral contraceptive pills on pap smear. Al-Qadisiyah Medical Journal. 2011;7(12):254-9.

13. Roura E, Travier N, Waterboer T, de Sanjosé S, Bosch FX, Pawlita M, et al. The influence of hormonal factors on the risk of developing cervical cancer and pre-cancer: results from the EPIC cohort. PLoS one. 2016 Jan 25;11(1):e0147029.

14. Binesh F, Akhavan A, Pirdehghan A, Davoodi M. Does oral contraceptive pill increase the risk of abnormal Pap smear?. Iranian journal of reproductive medicine. $2013 \mathrm{Sep} ; 11(9): 761$.

15. Oh HY, Kim MK, Seo SS, Lee JK. Association of combined tobacco smoking and oral contraceptive use with cervical intraepithelial neoplasia 2 or 3 in Korean women. Journal of epidemiology. 2016 Jan 5;26(1):22-9.

16. Sayednozadi S, Hassany M, Ramezani MA. Association of oral contraceptives and abnormal Pap smear. Am J Appl Sci. 2005 Jul;2(7):1150.

17. Adhikari I, Eriksson T, Luostarinen T, Lehtinen M, Apter D. The risk of cervical atypia in oral contraceptive users. The European Journal of Contraception \& Reproductive Health Care. 2018 Jan 2;23(1):12-7.

18. Xu H, Egger S, Velentzis LS, O'Connell DL, Banks E, Darlington-Brown J, et al. Hormonal contraceptive use and smoking as risk factors for high-grade cervical intraepithelial neoplasia in unvaccinated women aged 30-44 years: A casecontrol study in New South Wales, Australia. Cancer epidemiology. 2018 Aug 1;55:162-9.

19. Arbyn M, Herbert A, Schenck U, Nieminen P, Jordan J, McGoogan E, et al. European guidelines for quality assurance in cervical cancer screening: recommendations for collecting samples for conventional and liquid-based cytology. Cytopathology. 2007 Jun;18(3):133-9.

Attya, A., Ali, A., AbdelSalam, H., Abdelwahab, M. Frequency of Cervical Intra-epithelial Neoplasia in Oral Contraceptive Pills Users in Zagazig University Hospitals. Zagazig University Medical Journal, 2019; Jully. 2020 Volume 26 Issue 4 (590-597): -. doi: 10.21608/zumj.2019.13975.1275 